\title{
Heat flow from wet to dry snowpack layers and associated faceting
}

\author{
Bruge JAMieson ${ }^{1}$ Charles FierZ ${ }^{2}$ \\ ${ }^{1}$ Department of Civil Engineering, Department of Geology and Geophysics, University of Calgary, 2500 University Drive NW, Calgary, \\ Alberta T2N 1N4, Canada \\ E-mail@bruce.jamieson@ucalgary.ca \\ ${ }^{2}$ WSL Swiss Federal Institute for Snow and Avalanche Research SLF, Flüelastrasse 11, CH-7260 Davos-Dorf, Switzerland
}

\begin{abstract}
Layers of faceted crystals adjacent to crusts form the failure layers for some unexpected dry-slab avalanches. This paper focuses on the case of facets that form when dry snow overlies wet snow. From a basic equation for heat flow in solids, the approximate freezing time of the wet layer is derived. Seven experiments are described in which a wet layer was placed between two dry-snow layers in a cold laboratory. Measured freezing times are comparable to the freezing times from the approximate solution assuming that latent heat from the irreducible water content flowed up. In four of the experiments, evidence of faceting was observed at the base of the upper dry snow layer within 5 hours and before the wet layer froze. In all seven experiments faceting was observed in the upper dry layer after the wet layer froze. Simulations performed with the snowcover model SNOWPACK yield freezing times that agree reasonably with the approximate solution and allow the influence of various parameters on the results to be explored. In addition, simulated temperatures and grain evolution are compared with observations, showing good agreement.
\end{abstract}

\section{INTRODUCTION}

Some dry-slab avalanches that threaten people and property initiate in weak layers of faceted crystals on crusts within the mountain snowpack. The associated slab avalanche hazard may persist since these faceted layers can remain weak for weeks or months. There are various snowpack processes that cause kinetic growth (faceting) of crystals. We focus on the formation of faceted crystals directly above wet layers buried by dry snow. A dry snow layer overlying a wet layer is typically subjected to a temperature and vapour gradient caused by the upper surface of the dry snow layer being below the freezing point, while latent heat in the wet layer holds the lower boundary of the dry layer near the freezing point until the wet layer freezes.

In this paper, we derive an equation for the freezing time of the wet layer, compare the calculated values with measured freezing times from seven cold-laboratory experiments (Jamieson and Van Herwijnen, 2002), identify the faceting that occurred while the wet layer was unfrozen, assess the variables that influence the freezing time and hence sustain the temperature gradient in the overlying dry snow, and model the formation of faceted crystals in a dry layer overlying a wet layer with the Swiss model SNOWPACK (Bartelt and Lehning, 2002; Lehning and others, 2002a, b).

\section{LITERATURE REVIEW}

Birkeland (1998) described the various processes that lead to the formation of faceted crystals near the surface of the snowpack, including the formation of faceted crystals in dry snow overlying a wet layer. Fukuzawa and Akitaya
(1993) observed that a $60 \mathrm{~mm}$ wet layer under a $20 \mathrm{~mm}$ dry layer required 6 hours to freeze during which grains in the dry layer became faceted. Jamieson and others (2001) used weather data to argue that latent heat from a wet layer buried by dry snow in November 1996 contributed to the formation of faceted crystals in an overlying dry snow layer, which released over 700 large slab avalanches by 31 March 1997 in the Columbia Mountains, Canada. Also using weather data, Greene and Johnson (2002) argued that latent heat from a wet layer may have contributed to the formation of a faceted layer below a crust at lower elevations in the Wasatch Mountains, Utah, U.S.A. This faceted layer released over 200 slab avalanches over 70 days. In seven of seven cold-laboratory experiments, Jamieson and Van Herwijnen (2002) observed the growth of faceted crystals in a dry layer sieved onto a wet layer and subjected to subfreezing air temperature, but did not distinguish between faceting that occurred before and after freezing of the wet layer.

Armstrong (1985) modeled a $1 \mathrm{~m}$ thick layer of rainwetted snow that took 6 days to freeze during which the temperature gradient in the overlying layer of dry snow was favourable to faceting. Based on Carslaw and Jaeger's (1959) equations for heat flow in solids, Colbeck and Jamieson (2001) derived an equation for the unsteady temperature profile in dry snow overlying a wet layer, and an equation for the heat required until the temperature profile became constant. Using Colbeck's (1983) grain-growth model, they showed that substantial kinetic grain growth at the interface was likely within hours.

In this paper, we derive the freezing time of a wet layer buried by dry snow and compare calculated freezing times with freezing times measured during cold-laboratory 


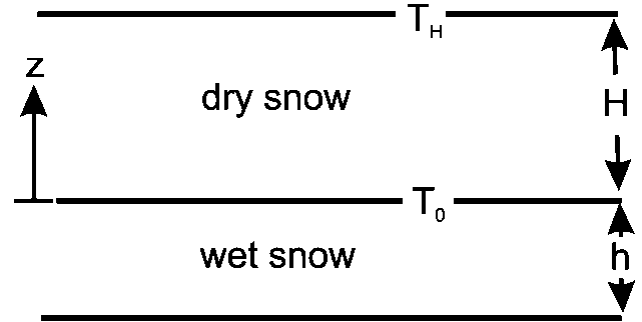

Insulation

Fig. 1. Model and nomenclature used for heat flow from a wet to a dry snowpack layer.

experiments. The freezing times and observed faceted crystals are also compared with those modeled by SNOWPACK (Bartelt and Lehning, 2002; Lehning and others, 2002a, b).

\section{THEORETICAL HEAT-FLOW MODEL}

The model consists of two snow layers (Fig. 1). The lower wet layer of thickness $h$ has liquid-water content (volume fraction) $\theta$ and is insulated at its base. The upper dry layer of thickness $H$ has a density $\rho$ and effective thermal diffusivity $\kappa$. While the wet layer remains unfrozen, the temperature of the interface between the two snow layers is $T_{0}=0^{\circ} \mathrm{C}$. The latent heat per unit area in the wet layer is $L \theta h$, where the latent heat per unit volume of water is $L=3.3 \times 10^{8} \mathrm{~J} \mathrm{~m}^{-3}$. The temperature of the dry layer is initially $T_{\mathrm{H}}<0^{\circ} \mathrm{C}$, and that of its upper surface is constant $T_{\mathrm{H}}<0^{\circ} \mathrm{C}$, causing heat to flow from the lower wet layer to the upper surface of the dry layer.

The temperature $T$ at time $t$ and depth $0 \leq z \leq H$ is given by Colbeck and Jamieson (2001) based on Kondrat'eva (1954) or Carslaw and Jaeger (1959):

$$
\begin{array}{r}
T=\frac{2}{\pi}\left(T_{\mathrm{H}}-T_{0}\right) \sum_{n=1}^{\infty} \frac{1}{n} \exp \left(-\frac{\kappa n^{2} \pi^{2} t}{H^{2}}\right) \sin \left(\frac{n \pi z}{H}\right) \\
+T_{\mathrm{H}}\left(\frac{z}{H}\right)+T_{0}\left(1-\frac{z}{H}\right) .
\end{array}
$$

Differentiating with respect to $z$ yields the unsteady temperature gradient in the dry layer

$$
T^{\prime}=\frac{2}{\pi}\left(\frac{T_{\mathrm{H}}-T_{0}}{H}\right)\left[\frac{1}{2}+\sum_{n=1}^{\infty} \exp \left(\frac{-\kappa n^{2} \pi^{2} t}{H^{2}}\right) \cos \left(\frac{n \pi z}{H}\right)\right],
$$

where $\left(T_{\mathrm{H}}-T_{0}\right) / H$ is the average temperature gradient across the dry snow layer.

Evaluating $T^{\prime}$ at the $z=0$ interface where the cosine term in Equation (2) becomes one, the wet layer will freeze at time $t_{\mathrm{f}}$ when the latent heat has flowed across the interface:

$$
L \theta h=-k \int_{0}^{t_{\mathrm{f}}} T^{\prime} \mathrm{d} t
$$

where the effective thermal conductivity of the dry layer is $k=\kappa \rho C_{\mathrm{p}}$ and $C_{\mathrm{p}}$ is the specific heat of ice or dry snow, approximately $2100 \mathrm{~J} \mathrm{~kg}^{-1}$. Thermal conductivity can be estimated from density or grain type (Sturm and others, 1997).

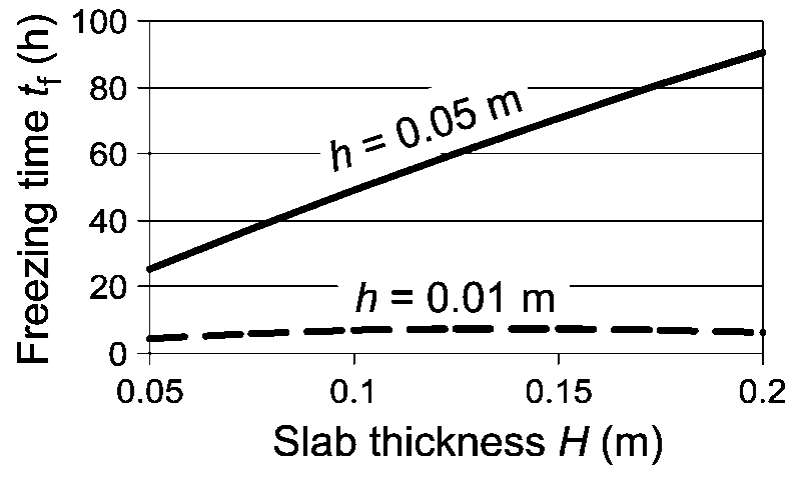

Fig. 2. Effect of thickness of slab and wet layer on freezing time for $\theta=0.048$ by volume, $\rho=80 \mathrm{~kg} \mathrm{~m}^{-3}, T_{\mathrm{H}}=-10^{\circ} \mathrm{C}$.

The freezing time is only weakly dependent on the thickness of the slab for the thin wet layer.

Evaluating the integral in Equation (3) yields

$$
\begin{gathered}
L \theta h=\kappa \rho C_{\mathrm{p}}\left(\frac{T_{0}-T_{\mathrm{H}}}{H}\right) \\
\cdot\left\{t_{\mathrm{f}}+2 \frac{H^{2}}{\kappa \pi^{2}}\left[\sum_{n=1}^{\infty} \frac{1}{n^{2}}-\sum_{n=1}^{\infty} \frac{1}{n^{2}} \exp \left(-\frac{\kappa n^{2} \pi^{2} t_{\mathrm{f}}}{H^{2}}\right)\right]\right\} .
\end{gathered}
$$

This equation implicitly gives the freezing time $t_{\mathrm{f}}$, in terms of the properties of the two layers and the boundary conditions.

To obtain an explicit approximation for $t_{\mathrm{f}}$, we seek simplification of the two infinite series in Equation (4). The first series equals $\pi^{2} / 6$. To show the second series is small compared to the first, we consider its range for 1 hour $\leq t_{\mathrm{f}} \leq 24$ hours and $0.05 \mathrm{~m} \leq H \leq 0.5 \mathrm{~m}$. Since freezing times will increase with the thickness of the dry layer $H$, we constrain $t_{\mathrm{f}} / H^{2}>250000 \mathrm{~s} \mathrm{~m}^{-2}$, approximately 70 hours $\mathrm{m}^{-2}$. For a $0.05 \mathrm{~m}$ thick dry layer, this constraint restricts freezing times to be at least $10 \mathrm{~min}$, and for a $0.5 \mathrm{~m}$ thick dry layer freezing times must be at least 17 hours, values which are consistent with the field observation of Fukuzawa and Akitaya (1993) and cold-laboratory experiments of Jamieson and Van Herwijnen (2002). Subject to this constraint, the second series ranges between 0 and $25 \%$ and averages $5 \%$ of the first series for 1 hour time-steps and $H=0.05 \mathrm{~m}, 0.1 \mathrm{~m}, 0.2 \mathrm{~m}, 0.35 \mathrm{~m}$ and $0.5 \mathrm{~m}$. Dropping the second and smaller series in Equation (4), the freezing time is approximated

$$
t_{\mathrm{f}} \approx \frac{L \theta h}{\kappa \rho C_{\mathrm{p}}}\left(\frac{H}{T_{0}-T_{\mathrm{H}}}\right)-\frac{H^{2}}{3 \kappa} .
$$

This approximation is, in fact, a lower bound since the second series in Equation (4) is always positive. Equation (5) can be compared with experimental values or field values since all the variables can be measured. However, boundary conditions are unlikely to be constant as assumed for the derivation of Equations (1-5). In particular, the theoretical model is insulated below the initially wet layer, whereas in most realistic snowpack conditions there are more snow layers below the initially wet layer, which can both drain liquid water and draw heat from the wet layer.

The effect of slab thickness and wet-layer thickness on freezing time (Equation (5)) for $\rho=80 \mathrm{~kg} \mathrm{~m}^{-3}, \theta=0.048$ and $T_{\mathrm{H}}=-10^{\circ} \mathrm{C}$ is shown in Figure 2. The thin wet layer, $h=0.01 \mathrm{~m}$, freezes within $4-8$ hours and with little 
dependence on slab thickness, $H=0.05-0.2 \mathrm{~m}$. The thicker wet layer requires 25-90 hours to freeze, with freezing time increasing with slab thickness.

\section{GOLD-LABORATORY EXPERIMENTS}

\section{Experimental methods}

Jamieson and Van Herwijnen (2002) describe seven experiments in the Rogers Pass (British Columbia, Canada) cold laboratory, which varied in length from 2 to 9 days. In each experiment a wet layer was located between dry layers, and the upper surface cooled below the freezing point. These three snow layers were placed in a box $(0.50 \mathrm{~m} \times 0.50 \mathrm{~m} \times 0.42 \mathrm{~m}$ high $)$ insulated on the sides and the base with $70 \mathrm{~mm}$ thick foam (Fig. 3). One wall of this box was removable to facilitate placing the basal block of snow and subsequent observations of crystals. The base layer for the experiments ranged in thickness from 0.10 to $0.21 \mathrm{~m}$ and consisted of a block of natural snow with a density of $200-300 \mathrm{~kg} \mathrm{~m}^{-3}$ that was slid laterally into the bottom of the box where it fit tightly. The middle layer consisted of wet snow made from mixing dry snow with liquid water and spreading the mixture onto the base layer. The thickness of the wet layer ranged from 0.015 to $0.09 \mathrm{~m}$ (Table 1), and was taken as the average thickness of the crust at the end of the experiment. The liquid water was calculated from the volume of liquid water added to the mixture divided by the cross-sectional area of the box. This was in excess of the irreducible liquid-water content. The upper layer (subsequently referred to as the slab) consisted of natural snow sieved onto the wet layer and ranged in thickness from 0.055 to $0.14 \mathrm{~m}$. The thickness of the slab was measured at the start and end of each multi-day experiment, and the initial thickness used for calculations. The density of the dry slab was measured at the end of each experiment with a $10^{-4}$ $\mathrm{m}^{3}$ cylindrical sampler and digital weigh scale. Twelve thermistors, calibrated to within $0.1{ }^{\circ} \mathrm{C}$ of $0^{\circ} \mathrm{C}$ in slush, were placed through the side of the box and $0.010-0.055 \mathrm{~m}$ vertically apart in the wet layer and overlying dry snow. Depending on the thickness of the wet layer, there were one to three

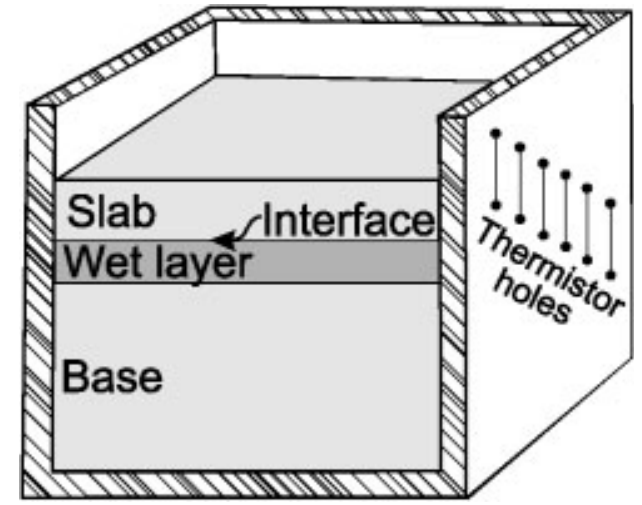

Fig. 3. Perspective diagram of insulated box used for measuring temperature profiles and changes in snow crystals in the dry snow ( slab) above the wet layer. The inside dimensions of the box are $0.50 \mathrm{~m}$ by $0.50 \mathrm{~m}$ by $0.42 \mathrm{~m}$ high. The insulated front door of the box is removable and not shown.

thermistors placed in it. The temperature of each thermistor was measured every minute and the average temperature of each thermistor was recorded every $30 \mathrm{~min}$ by a datalogger. During each observation, the removable wall of the box was detached to facilitate extraction of crystals from the base and middle of the slab. For each observation, sampling of crystals was at least $0.05 \mathrm{~m}$ from the site of previous samples and from any wall. The grains at the base and middle of the slab were observed through an $8 \times$ hand lens and a microscope, and classified according to Colbeck and others (1990) at least once per day for the first few days. For the first two experiments, a control block consisting of dry snow sieved onto a dry base layer was prepared, and the crystals observed in the upper dry layer. The air temperature in the cold laboratory varied from $-8^{\circ}$ to $-16^{\circ} \mathrm{C}$ several times per day according to the cycles of the compressor. The average air temperature during the freezing time was used as the surface temperature in Equation (5).

\section{Observations}

Settlement of the dry slab over the multi-day experiments averaged $0.01 \mathrm{~m}$. No gaps formed between the three-layer

Table 1. Observations for cold-laboratory experiments

\begin{tabular}{|c|c|c|c|c|c|c|c|c|c|c|c|c|c|}
\hline \multirow[t]{2}{*}{$\begin{array}{l}\text { Start } \\
\text { date } \\
2002\end{array}$} & \multirow{2}{*}{$\begin{array}{c}\text { Duration } \\
\text { days }\end{array}$} & \multirow[t]{2}{*}{$\begin{array}{c}\text { Number } \\
\text { of } \\
\text { obs. }\end{array}$} & \multirow[t]{2}{*}{$\begin{array}{c}\text { Thickness, } \\
\qquad h \\
\\
\text { m }\end{array}$} & \multirow{2}{*}{$\begin{array}{l}\text { Liquid } \\
\text { water } \\
\text { added } \\
\\
\\
\mathrm{mm}\end{array}$} & \multirow[t]{2}{*}{$\begin{array}{l}\text { Time } \\
\text { to } \\
\text { freeze } \\
\quad t_{\mathrm{f}} \\
\\
\text { hours }\end{array}$} & \multirow{2}{*}{$\begin{array}{c}\text { Avg. air } \\
\text { temp. during } \\
\text { freezing of } \\
\text { wet layer }{ }^{1} \\
T_{\mathrm{H}} \\
{ }^{\circ} \mathrm{C}\end{array}$} & \multirow{2}{*}{$\begin{array}{c}\text { Thickness } \\
\text { at start } \\
\text { of exp. } \\
H \\
\\
\\
\text { m }\end{array}$} & \multirow{2}{*}{$\begin{array}{c}\text { Density } \\
\qquad \begin{array}{c}\rho \\
\mathrm{kg} \mathrm{m}^{-3}\end{array}\end{array}$} & \multirow[t]{2}{*}{$\begin{array}{c}\text { Initial grain } \\
\text { form at } \\
\text { interface } \\
\text { (Colbeck } \\
\text { and others } \\
\text { 1990) }\end{array}$} & \multirow{2}{*}{$\begin{array}{c}\text { Initial } \\
\text { faceting }^{\text {interval }^{2}} \\
\\
\text { hours }\end{array}$} & \multicolumn{2}{|c|}{$\begin{array}{l}\text { Time to first } \\
\text { obs. of facets } \\
\text { as dominant } \\
\text { grain form }\end{array}$} & \multirow[t]{2}{*}{$\begin{array}{l}\text { Final grain } \\
\text { form at } \\
\text { interface }\end{array}$} \\
\hline & & & & & & & & & & & hours & hours & \\
\hline 14 Feb. & 6.9 & 6 & 0.015 & 4.3 & 5 & -15.5 & 0.065 & 203 & $/ 0.5-1,+1-1.5$ & $0-17$ & 24 & 72 & $\square 0.5$ \\
\hline 21 Feb. & 8.7 & 7 & $0.035^{3}$ & 7.1 & 11 & -14.8 & 0.14 & 143 & $+3-4, / 1-2$ & $0-17$ & 25 & 40 & $\square 0.5 / 0.5-1$ \\
\hline 11 Mar. & 4.8 & 3 & 0.025 & 7.5 & 9.5 & -12.1 & $0.06^{4}$ & 201 & $0.5-1$ & $0-21$ & 51 & 51 & $\square 0.5-0.8$ \\
\hline 16 Mar. & 4.8 & 6 & $0.075^{3}$ & 20.7 & 21.5 & -9.3 & 0.055 & 141 & $+1, / 0.5-1$ & $0-2$ & 7 & 20 & $\square \wedge 1-1.5$ \\
\hline 21 Mar. & 3.7 & 6 & $0.09^{3}$ & 11.3 & 8 & -15.0 & 0.12 & 248 & $/ 0.5^{-1}, \square 0.5$ & $0-3$ & 3 & 3 & $\square 0.5-0.8$ \\
\hline 25 Mar. & 1.9 & 4 & $0.04^{3}$ & 11.3 & 9 & -12.2 & 0.08 & 339 & $0.5^{-1}$ & $0-5$ & 5 & 5 & $\square 0.5-0.8$ \\
\hline 27 Mar. & 3.8 & 8 & $0.06^{3}$ & 15.1 & 9.5 & -14.0 & 0.06 & 138 & $/ 1,+1-1.5$ & $0-2$ & 2 & 20 & $\square 0.3-1$ \\
\hline
\end{tabular}

\footnotetext{
1 In the cold laboratory, the surface temperature is assumed equal to the air temperature.

2 First evidence of faceting observed at the end of this interval at $30 \times$ magnification (e.g. faceted crystals as the dominant or minor grain type, or new edges on grains).

3 Evidence of liquid water draining into the base layer.

4 Sieving snow was initially moist when sieved.
} 


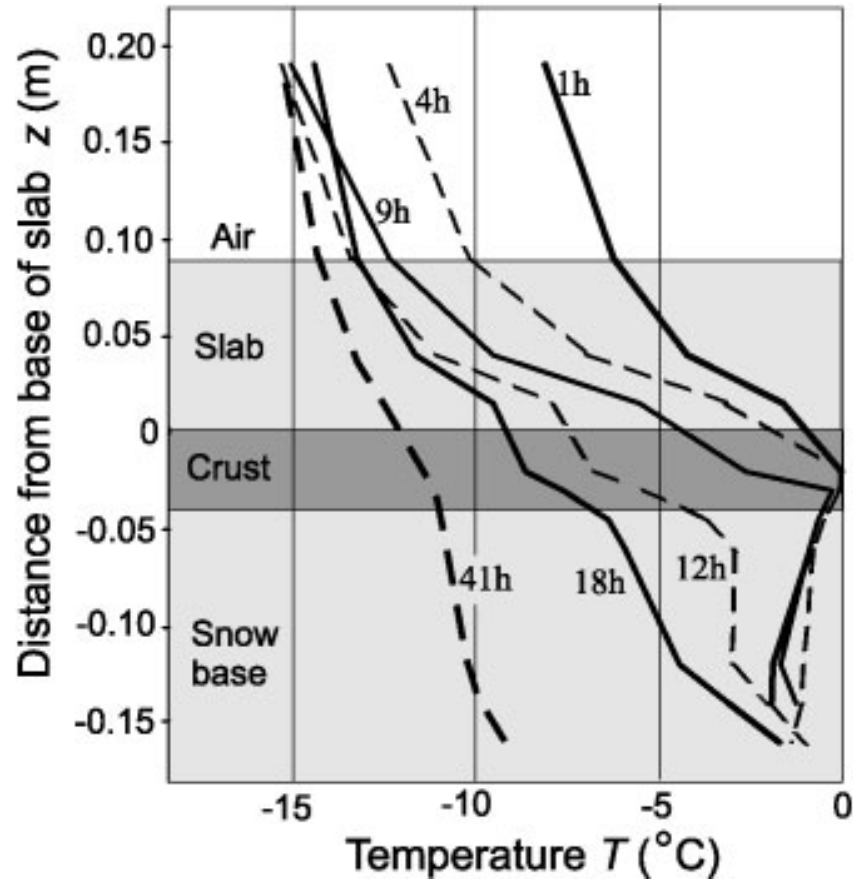

Fig. 4. Six temperature profiles after 1-41 hours from the experiment started on 25 March 2002. The profiles show that part of the middle layer ("crust") was wet for approximately 9 hours.

snowpacks and the fixed walls of the box, although ice forming at the base of the box tended to push the removable wall away from the snowpack, often resulting in a gap of 0.02-0.04 m.

Except for the experiments that started on 14 February and 11 March 2002, frozen percolation channels in the base layer and/or ice at the bottom of the base layer were observed, or warming to near the freezing point occurred in the base layer, indicating that liquid water drained from the wet layer.

The temperature profiles show the middle layer was at $0^{\circ} \mathrm{C}$ in all experiments for at least 2 hours. In Figure 4, we show six temperature profiles after 1-41 hours from the experiment that started on 25 March 2002 to exemplify the evolution of heat flow. The thermistors located at $z=-0.02 \mathrm{~m}$ and $z=-0.03 \mathrm{~m}$ were at $0^{\circ} \mathrm{C}$ after 1 and 4 hours, but only the thermistor at $z=-0.03 \mathrm{~m}$ was at $0^{\circ} \mathrm{C}$ after 9 hours. During this period the strong temperature gradient in the slab was drawing heat upwards; the base layer was at $-1^{\circ}$ to $-2^{\circ} \mathrm{C}$ and had little gradient, likely because liquid water from the wet layer drained through percolation channels into the base layer. The wet layer was deemed to have frozen after 9 hours, when the last thermistor in the wet layer dropped below $-0.5^{\circ} \mathrm{C}$. The temperature profiles at 12 and 18 hours show that the initially wet layer had frozen into a crust and was cooling. The temperature gradient in the slab was decreasing but was still sufficient for faceting $\left(<10-20^{\circ} \mathrm{C} \mathrm{m}^{-1}\right.$ ) (de Quervain, 1958; Akitaya, 1974; Colbeck, 1983), and the temperature gradient in the base layer had increased, likely because of liquid water at the bottom of the base layer. After 41 hours, the base layer was cooling and the temperature gradient in all three layers was decreasing.

In all seven experiments with the initially wet layer, evidence of faceting was observed at the base of the slab after the first post-set-up observation. In the last four experiments this was within 5 hours or less and before the wet layer froze (Table 1). In the first three experiments, faceting was observed in the first post-set-up observation after 1721 hours, but at least 6 hours after the wet layer froze. Faceting was not observed before the wet layer froze in the first three experiments either because it did not occur or because the first post-set-up observation was too late. The initial and final grain types and their size along with the thickness of the layers, the density of the dry layer and the freezing time of the wet layer are shown in Table 1 for each experiment. As the dominant grain form, faceted crystals were observed at the interface before they were observed in the middle of the slab in four of the seven experiments and during the same observation in the remaining three experiments.

For the first two experiments in which control blocks were prepared without the middle wet layer, no faceting was observed in the upper dry snow layer, indicating that the wet layer was necessary for the observed faceting of the slab.

\section{COMPARISON WITH THEORETIGAL MODEL}

We compare the freezing times from the experiments with values from the theoretical model since both approaches provide the freezing time, and these were measured to within 0.5 hours in the experiments. However, several of the conditions for these experiments were not the same as assumed for the theoretical model. The air temperature in the cold laboratory, and hence the surface temperature of the slab, varied during the experiments. The initial temperature of the slab was likely not $T_{\mathrm{H}}$ throughout its thickness. The wet layer likely froze at its upper boundary first, causing the interface temperature to fall below $0^{\circ} \mathrm{C}$ before the wet layer froze throughout its thickness. Most importantly, since the liquid water added was well above the irreducible water content $\theta_{\text {IRR }}$ of approximately 0.048 by volume (Coléou and Lesaffre, 1998), drainage was expected in all experiments. We assume the latent heat associated with the irreducible liquid-water content flowed upwards and the excess liquid-water content drained, warming the base layer. Consequently, we use $\theta=\theta_{\text {IRR }}$ in Equation (5). Thermal diffusivity $\kappa$ of the slab was calculated from $k / \rho C_{\mathrm{p}}$ after thermal conductivity $k$ was calculated from the density of the slab (Sturm and others, 1997). The calculated freezing times are plotted against the measured freezing times in Figure 5. Excluding the experiment that started on 21 March 2002, the remaining calculated freezing times are comparable to corresponding measured values (coefficient of determination, $R^{2}=0.83$; average error $59 \%$ ). The wet layer in the experiment that started on 21 March 2002 froze much faster than the calculated freezing time; perhaps the wet layer was locally thinner near the thermistors. Including this experiment increases the average error to $87 \%$ and $R^{2}$ drops to 0.47 . Given the substantial differences in boundary and initial conditions between the theoretical model and the experiments, approximate freezing times from Equation (5) show reasonable agreement with measured freezing times. Also, six of the seven measured freezing times show the same trend as calculated freezing times, indicating that the effect of the variables $H, h, k, \rho, T_{\mathrm{H}}$ and $\theta=\theta_{\mathrm{IRR}}$ is appropriately represented in Equation (5).

Using the data from Table 1, freezing times from the approximate solution (Equation (5)) can be compared with times from the implicit solution (Equation (4)). The differences are $<0.2 \%$ except for the first experiment, which 
Table 2. Element properties in the wet and basal layer for SNOWPACK simulations

\begin{tabular}{lcclcc}
\hline Layer & $\begin{array}{c}\text { Drydensity } \\
\mathrm{kg} \mathrm{m}^{-3}\end{array}$ & $\begin{array}{c}\text { Grain-size } \\
\mathrm{mm}\end{array}$ & Grainform $^{1}$ & $\begin{array}{c}\text { Dendricity } \\
(0-1)\end{array}$ & $\begin{array}{c}\text { Sphericity } \\
(0-1)\end{array}$ \\
\hline Wet & 330 & 1.2 & $\bigcirc \bigcirc$ & 0.0 & 1.0 \\
Basal & 250 & 0.5 & $\bullet$ & 0.0 & 0.5 \\
\hline
\end{tabular}

* Colbeck and others (1990).

differs by $7.6 \%$. This shows the utility of the approximate solution for a range of conditions similar to those found in the experiments.

\section{COMPARISONS WITH SIMULATION}

\section{Simulation model}

The one-dimensional snow-cover model SNOWPACK solves the unsteady heat-transfer and creep/settlement equations using a Lagrangian finite-element method. A full description of the model is beyond the scope of this paper, and the reader is referred to the publications by Bartelt and Lehning (2002) and by Lehning and others (2002a, b).

In the present application, temperatures measured at the air/surface interface as well as $T_{\mathrm{B}}$ recorded by the lowest thermistor were used as Dirichlet boundary conditions for the model. Regarding thermal conductivity, Fierz and Lehning (2001) showed that SNOWPACK's implementation follows quite closely the density-dependent equation given by Sturm and others (1997). Finally, note that grain form was coded as a combination of the model parameters sphericity and dendricity (Lesaffre and others, 1998; Fierz and Baunach, 2000). Sphericity is 0 for fully faceted grains and 1 for fully rounded grains (e.g. small rounds or wet grains). A dendricity larger than 0 is assigned to new-snow and decomposing particles, the size of which is set to $0.3 \mathrm{~mm}$ by default. Those assignments are somewhat user-dependent and may substantially affect grain evolution. For instance, grain growth does not start before dendricity reaches 0 .

To initialize the model, the bulk properties of each layer as given in Table 1 were assigned to a suitable number of finite elements. Accordingly, for all experiments except the one started on 25 March 2002, initial dendricity and initial sphericity in the slab were both set to values greater than zero. Bulk properties for the base layer as well as for the wet layer were assumed to be the same for all experiments (Table 2) except for the initial liquid-water content in the wet layer (Table 3). Irreducible water content was fixed to 0.048 by volume for all layers. Element temperatures at the beginning of a simulation run were inferred from corresponding measured temperature profiles. Simulated freezing time was defined as the point at which all liquid water pres-

Table 3. Comparison of cold laboratory experiments with SNOWPACK simulations

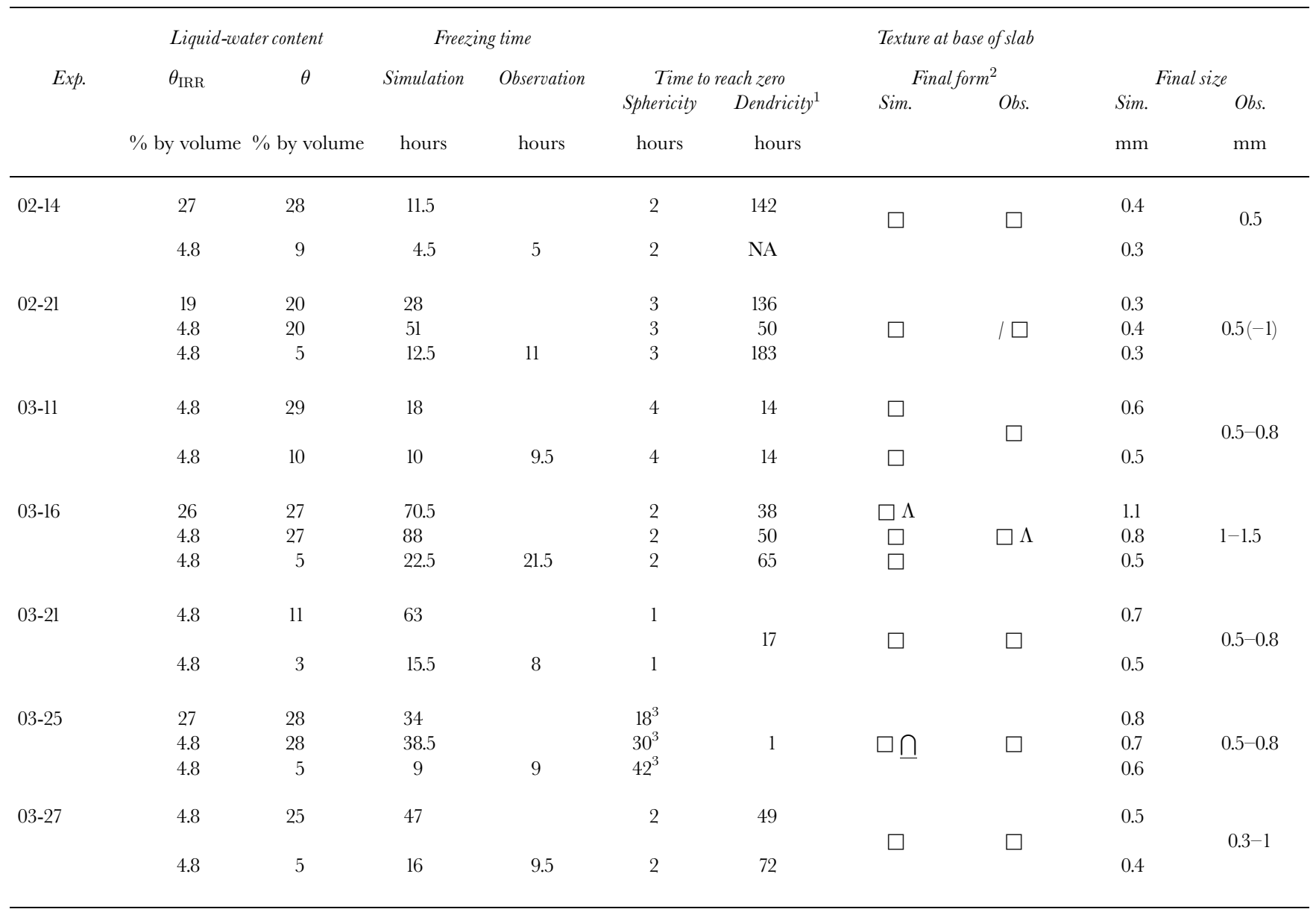

\footnotetext{
1 NA means dendricity was still larger than zero at the end of the simulation.

2 Colbeck and others (1900).

3 Time at which sphericity gets smaller than 0.5 at interface.
} 


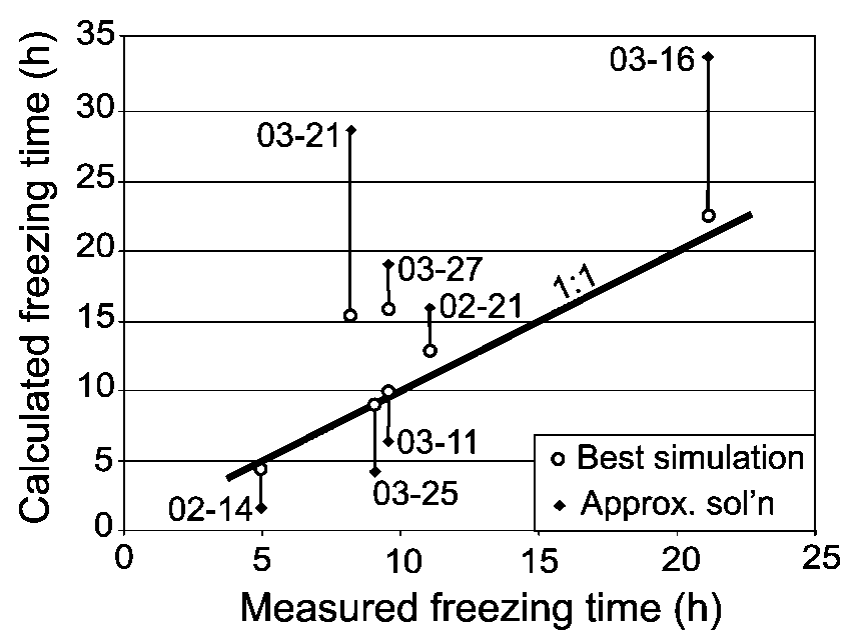

Fig. 5. Comparison of measured freezing times from seven cold-laboratory experiments with freezing times simulated by SNOWPACK and calculated freezing times assuming that latent heat associated with the irreducible liquid-water content flows up from the wet layer into the dry layer. The 1:1 line shows that calculated and simulated freezing times are comparable to measured values for six of the seven experiments and exhibit the same trend.

ent anywhere in the snowpack freezes, which in most cases corresponds to the bottom of the wet layer. In any case, though, this time was found to be shorter by no more than an hour as compared to the temperature of the corresponding model element dropping below $-0.5^{\circ} \mathrm{C}$. Thus, for the sake of comparison, the longer times are shown in Table 3 along with the experimentally determined freezing times.

\section{Comparison of simulations with approximate solution}

Assumptions of the theoretical model presented above are that no heat may flow downwards from the wet layer, and that it holds all the liquid water added. We simulated this situation by setting the irreducible water content close to the value corresponding to $100 \%$ of water added (Table 3 ). Resulting freezing times were two to four times longer than the observed freezing times, though. Still adding $100 \%$ of water to the wet layer but setting the irreducible water content to 0.048 by volume, SNOWPACK allowed the excess water to percolate instantaneously into the lower layer, thereby warming the whole base to the freezing point (see Fig. 6). However, this approach led to even longer simulated freezing times than previously found.

Finally, we sought a "best-fit" solution not only by matching observed and simulated refreezing times but also by considering a closest agreement of simulated with measured temperatures at various heights within the three-layer pack. Best results were obtained for the liquid-water contents $\theta$ shown in Table 3 . Note that $\theta$ amounted to at most twice the fixed irreducible water content of 0.048 by volume corresponding to the dry density of the wet slab (Coléou and Lesaffre, 1998). This agrees well with the assumption made for the theoretical model above, but it also means we had to assume that most of the liquid water drained through to the bottom even before the first recorded temperature profile. The reasonable agreement of "best-fit" simulations with both measured and approximated freezing times is shown in Figure 5. The consistent overestimation of freezing
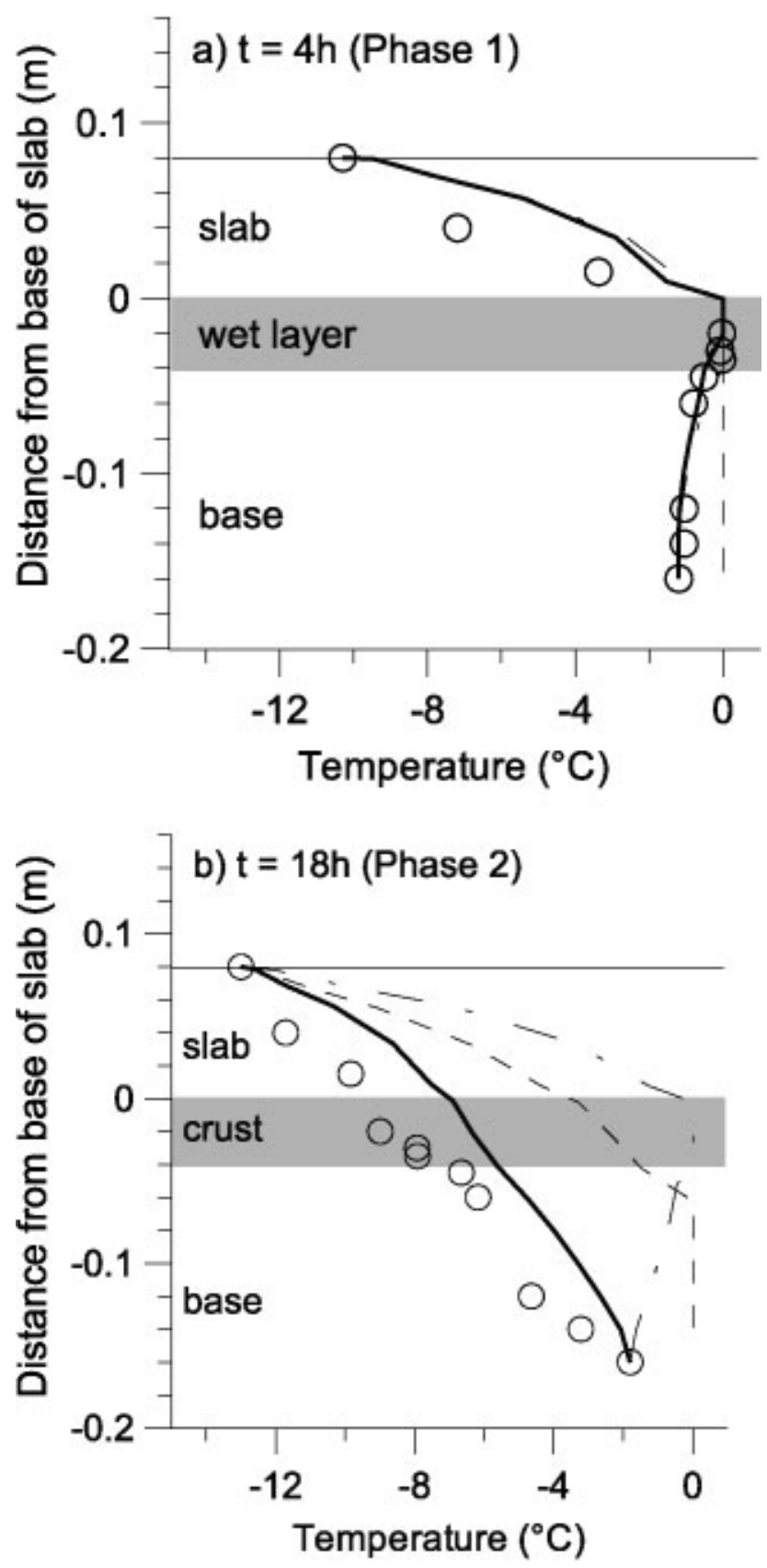

Fig. 6. Comparison of measured with simulated temperature profiles for the experiment started on 25 March 2002: (a) 4 hours after experiment started (phase 1); (b) 18 hours after experiment started (phase 2). Open circles: measurement; solid line: simulation with $\theta=0.05$ and $\theta_{\mathrm{IRR}}=0.048$ by volume; dashed line: simulation with $\theta=0.28$ and $\theta_{\mathrm{IRR}}=0.048$ by volume; dot-dashed line: simulation with $\theta=0.28$ and $\theta_{\mathrm{IRR}}=0.27$ by volume.

time even by "best-fit" simulations may be due to the fact that heat removed by evaporation of some liquid water present in the wet layer was not properly taken into account.

\section{Comparison of simulations with experiments}

In Figure 6 we show measured temperature profiles from the experiment started on 25 March 2002 along with simulated temperature profiles for different settings of irreducible water content $\theta_{\mathrm{IRR}}$ and water-added $\theta$. Clearly, simulation with $\theta=0.05$ and $\theta_{\mathrm{IRR}}=0.048$ showed closest agreement during both phases 1 and 2 of the refreezing process. Note, however, that artificially holding $100 \%$ of the liquid water in the wet layer had little effect on the simulation 
results during phase 1 . Indeed, differences were clearly apparent during phase 2 only, where stronger temperature gradients were sustained for a longer period of time if excessive water was added. This, in turn, led to more kinetic growth at the interface, as may be seen from the final simulated grain-size for all experiments and in the simulated grain form in the experiment started on 16 March 2002 (Table 3). However, defining the time at which sphericity became zero as the end of initial faceting, column 6 of Table 3 shows this happened within a few hours after the experiments started, except for the one started on 25 March 2002 which had initially small rounded grains (sphericity $=0.6$, dendricity $=0$ ). Again, this is in qualitative agreement with observation.

Finally we note that, as expected, faceting and kinetic grain growth in the base layer was also predicted by SNOWPACK. However, due to the lack of observations for this layer, no comparison can be made.

\section{DISGUSSION}

Equation (5) can be used to assess the effects of different variables on the freezing time and hence on the time during which a strong temperature gradient favourable to the kinetic growth of crystals exists in the overlying dry snow. The first term is proportional to the dry-snow thickness $H$. For dry-snow density $\rho=80 \mathrm{~kg} \mathrm{~m}^{-3}$, surface and initial slab temperature $T_{\mathrm{H}}=-10^{\circ} \mathrm{C}$ and $h=0.095 \mathrm{~m}$, the freezing time increases five-fold as $H$ increases six-fold from $0.05 \mathrm{~m}$ to $0.3 \mathrm{~m}$.

Model simulations take account of all layers involved as well as of their characteristics, which are inferred from observations (Table 1). One advantage of simulations, however, is the possibility of running the same experiments while varying either $\theta$ or $\theta_{\text {IRR }}$ or both in order to corroborate simpler solutions such as the approximate one for calculating freezing times. Thus we may explore the consequences of extreme settings. Obviously, putting and holding $100 \%$ of water in the wet layer does not reproduce the experiment. It may mimic an impeding horizon such as an ice lens underlying the wet layer, though. In that case, simulations show to what extent faceting and kinetic growth could be enhanced (see Table 3). As stated previously, grain growth will only start once dendricity is zero. Thus, final grain-size will depend on how efficiently dendricity is reduced, which in turn depends strongly on the temperature gradient at the interface. Here observed trends are qualitatively well reproduced by "best-fit" simulations.

Since faceting at the base of the slab was observed prior to freezing in four experiments and in the first observation after freezing in the remaining three experiments, the kinetic growth process is initially dominant. While the assumptions behind the theoretical model were often not fulfilled in the experiments, the strong temperature gradient was sufficient for faceting during the measured freezing time or, in most cases, during the approximated freezing time. Hence, Equation (5) provides a simple estimate of the time during which the temperature gradient is conducive to faceting.

\section{CONGLUSIONS}

The temperature regime after a wet layer is buried by dry snow can be divided into two phases: freezing of the wet layer (phase 1), and subsequent decay of the temperature profile to a quasi-steady-state temperature profile (phase 2). Strong temperature gradients conducive to faceting occur, especially at the interface between the dry and wet layers, during the heat flow from a freezing wet layer into an adjacent dry layer. The duration of the strong heat flow can be estimated from Equation (5). In addition to the factors in this equation, the freezing time will depend on the time during which the wet layer is exposed to cold air prior to burial by dry snow, and on the time over which the dry layer accumulates.

Application of Equation (5) to practical problems such as avalanche forecasting will require measurement of the thickness of the wet and overlying dry layer, the density of the dry layer and the surface temperature. Partial freezing of the wet layer and gradual accumulation of the overlying dry layer will limit the utility of this equation for freezing time. However, given reliable meteorological input data, snow-cover models such as SNOWPACK will obviate these estimations and the assumed constant boundary conditions. Indeed, subject to the limitations of a series of cold-laboratory experiments, either the approximate solution developed in this paper or SNOWPACK simulations can be used to estimate the freezing time during which kinetic growth of crystals at the base of the dry layer is intense.

Four of the seven cold-laboratory experiments showed faceting within 5 hours or less during which the wet layer was freezing. All seven experiments showed faceting during the decay of the temperature gradient after the wet layer froze. These observations were qualitatively reproduced by SNOWPACK too, showing the usefulness of snow-cover models to provide information beyond the approximation of freezing time only.

\section{ACKNOWLEDGEMENTS}

We are very grateful to S. Colbeck, A. van Herwijnen and C. Stethem for discussions of near-wet-layer faceting, to M. Lehning for fruitful discussions of SNOWPACK simulations and to M. Sturm, K. Birkeland and B. C. Johnson for constructive comments on the manuscript. A. van Herwijnen, K. Stewart, A. Zeidler, P. Langevin, M. Gagnon, J. Olson and I. Storm helped set up the experiments in the cold laboratory and made patient observations. Our thanks to D. McClung and Parks Canada for use and maintenance of the cold laboratory at Rogers Pass. The Glacier National Park Avalanche Control Section including D. Skjönsberg, B. McMahon, J. Kelly and J. Goodrich provided a stimulating environment for research. We thank W. Amman for his continuing support and his interest in this work and are grateful to him and J. Schweizer for inviting the first author to the Swiss Federal Institute for Snow and Avalanche Research in Davos, Switzerland, during summer 2002. The first author is grateful to the British Columbia Helicopter and Snowcat Skiing Operators Association, the Natural Sciences and Engineering Research Council of Canada, Canada West Ski Areas Association and the Canadian Avalanche Association for financial support.

\section{REFERENGES}

Akitaya, E. 1974. Studies on depth hoar. Contrib. Inst. Low Temp. Sci., Ser. A, 26. Armstrong, R. L. 1985. Metamorphism in a subfreezing, seasonal snow cover: the role of thermal and vapor pressure conditions. (Ph.D. thesis, University of Colorado.) 
Bartelt, P. and M. Lehning. 2002. A physical SNOWPACK model for the Swiss avalanche warning. Part I. Numerical model. Cold Reg. Sci. Technol., $35(3), 123-145$

Birkeland, K.W. 1998. Terminology and predominant processes associated with the formation of weak layers of near-surface faceted crystals in the mountain snowpack. Arct. Alp. Res., 30(2), 193-199.

Carslaw, H. S. and J. C. Jaeger. 1959. Conduction of heat in solids. Second edition. Oxford, Clarendon Press.

Colbeck, S. C. 1983. Theory of metamorphism of dry snow. 7. Geophys. Res., 88(C9), 5475-5482.

Colbeck, S. C. and J. B. Jamieson. 2001. The formation of faceted layers above crusts. Cold Reg. Sci. Technol., 33(2-3), 247-252.

Colbeck, S. C. and 7 others. 1990. The international classification for seasonal snow on the ground. Wallingford, Oxfordshire, International Association of Scientific Hydrology. International Commission on Snow and Ice.

Coléou, C. and B. Lesaffre. 1998. Irreducible water saturation in snow: experimental results in a cold laboratory. Ann. Glaciol., 26, 64-68.

De Quervain, M. R. 1958. On metamorphism and hardening of snow under constant pressure and temperature gradient. International Association of Scientific Hydrology Publication 46 (General Assembly of Toronto $1957-$ Snow and Ice), Vol. 4, 225-239.

Fierz, C. and T. Baunach. 2000. Quantifying grain-shape changes in snow subjected to large temperature gradients. Ann. Glaciol., 31, 439-444.

Fierz, C. and M. Lehning. 2001. Assessment of the microstructure based snow-cover model SNOWPACK: thermal and mechanical properties. Cold Reg. Sci. Technol., 33(2-3), 123-132.
Fukuzawa, T. and E. Akitaya. 1993. Depth-hoar crystal growth in the surface layer under high temperature gradient. Ann. Glaciol., 18, 39-45.

Greene, E. and G. Johnson. 2002. Characterization of a deep instability. In Stevens, J. R., ed. International Snow Science Workshop 2002, 29 September-4 October 2002, Penticton, British Columbia. Proceedings. Victoria, B.C., B.C. Ministry of Transportation. Snow Avalanche Programs, 491-498.

Jamieson, B. and A. van Herwijnen. 2002. Preliminary results from controlled experiments on the growth of faceted crystals above a wet snow layer. In Stevens, J. R., ed. International Snow Science Workshop 2002, 29 September-4 October 2002, Penticton, British Columbia. Proceedings. Victoria, B.C., B.C. Ministry of Transportation. Snow Avalanche Programs, 337-342.

Jamieson, J. B., T. Geldsetzer and C. Stethem. 2001. Forecasting for deep slab avalanches. Cold Reg. Sci. Technol., 33(2-3), 275-290.

Kondrat'yeva, A. S. 1954. Thermal conductivity of the snow cover and physical processes caused by the temperature gradient. SIPRE Transl. 22.

Lehning, M., P. Bartelt, B. Brown, C. Fierz and P. Satyawali. 2002a. A physical SNOWPACK model for the Swiss avalanche warning. Part II. Snow microstructure. Cold Reg. Sci. Technol., 35(3), 147-167.

Lehning, M., P. Bartelt, B. Brown and C. Fierz. 2002b. A physical SNOWPACK model for the Swiss avalanche warning service. Part III. Meteorological forcing, thin layer formation and evaluation. Cold Reg. Sci. Technol., 35(3), 169-184.

Lesaffre, B., E. Pougatch and E. Martin. 1998. Objective determination of snow-grain characteristics from images. Ann. Glaciol., 26, 112-118.

Sturm, M., J. Holmgren, M. König and K. Morris. 1997. The thermal conductivity of seasonal snow. F. Glaciol., 43(143), 26-41. 